\title{
Classe média e reformismo altermundialista
}

\author{
Ana Elisa Cruz Corrêa ${ }^{1}$
}

Resumo: Buscaremos demonstrar neste artigo que a posição de classe média dos integrantes do movimento altermundialista é uma questão fundamental para compreendermos a caracterização e os limites desse movimento social. Privilegiamos, neste sentido, a importância da classe média para a análise da luta de classes atual, ao considerarmos as relações da sua atuação política com a frágil situação do movimento operário e o fortalecimento de frações burguesas com o advento do capitalismo neoliberal.

Palavras-Chave: Classe média, altermundialismo, neoliberalismo, reformismo.

Abstract: This aim of this article is to show that the middle class position of the altermundialist movement is an essential point to understand the characteristics and limits of this social movement. Therefore, we affirm the great importance of the middle class to the analysis of class struggle, considering the relations between its political action, the fragility of workers movement and the strength of the dominants class fractions after the advent of neoliberalism.

Keywords: Middle class, altermundialism, neoliberalism, reformism.

"A história de toda sociedade até hoje é a história de luta de classes". Neste trecho notoriamente conhecido do Manifesto do Partido Comunista de Marx e Engels (1988, p. 66) encontramos a contundente afirmação sobre a importância da análise das classes sociais. Nesse momento, Marx se refere mais especificamente à burguesia e ao proletariado, não desenvolvendo suas análises sobre uma outra classe, que desponta em sua época, expande-se e se consolida amplamente durante o século XX: a pequenaburguesia ${ }^{2}$.

1 Guaduada em Ciências Sociais pela Universidade Estadual de Campinas (Unicamp). Correio eletrônico: aecorrea@ gmail.com

2 Apesar do crescimento da classe média ser contestado por diversos autores, sustentamos que essa classe se ampliou no decorrer do século XX. Dados que explicitam isso podem ser encontrados em Saes (1985) e Pochmann et al (2006).

cadernos cemarx, $\mathrm{n}^{\mathrm{o}} 5-2009 \quad 155$ 
Considerando o abalo que sofreu o marxismo nas últimas décadas em decorrência, dentre outros fatores, do peso ideológico da queda do muro de Berlim, do recuo do movimento operário e do avanço neoliberal em escala mundial, entendemos que uma das grandes tarefas da produção acadêmica marxista atual é buscar compreender sua realidade histórica. E, mais especificamente, refletir sobre as transformações pelas quais passa a ofensiva capitalista e a estrutura de classes no último século. Assim, sustentamos que o crescimento da classe média no século XX e sua atuação na dinâmica da luta de classes é uma questão fundamental a ser analisada pelos estudiosos dos movimentos sociais e, principalmente, por aqueles que discutem e empregam as análises marxistas em suas investigações. É essa, portanto, uma questão fundamental para a compreensão de grande parte das dificuldades e vicissitudes enfrentadas pelo movimento operário e do fortalecimento de frações burguesas através da roupagem neoliberal do sistema capitalista. Tendo esse pressuposto como pano de fundo, o objetivo deste artigo é apresentar o resultado - parcial - de nossa pesquisa sobre a composição de classe média do movimento altermundialista e sua importância para a compreensão das tendências reformistas presentes nesse movimento 3 .

Desenvolveremos, em um primeiro momento, uma breve discussão sobre a importância do conceito de pequena-burguesia para a análise de alguns momentos históricos, bem como para as análises dos atuais movimentos sociais. Em seguida, indicaremos alguns dados que apresentam a composição de classe do movimento altermundialista e faremos um pequeno comentário sobre a definição do conceito "classe média". Por fim, buscaremos demonstrar, a partir da análise de três pontos de caracterização do movimento (causas do seu surgimento, reivindicações e alternativas), suas tendências reformistas.

\section{A pequena-burguesia e a luta de classes}

Em O Dezoito Brumário de Luís Bonaparte, Marx (1980) desenvolve uma análise da luta de classes do processo histórico pelo qual a França atravessa, ressaltando a importância da classe pequeno-burguesa nas movimentações políticas nesse país. Essa classe, composta de pequenos-proprietários, apóia amplamente a revolução de 1848 , liderada pela burguesia e empreendida pelo proletariado. Com o advento da

3 Neste artigo abordamos os resultados parciais de uma pesquisa de iniciação científica, que deu origem a uma monografia foi defendida em julho de 2007. Grande parte das questões aqui presentes são também fruto de discussões realizadas no grupo de pesquisa "Neoliberalismo e Relações de Classe", sediado no Centro de Estudos Marxistas (Cemarx/ Unicamp).

156 Classe média e reformismo altermundialista 
República, os pequeno-burgueses se deparam com sua terrível condição financeira e limitada atuação política. Em situação de desespero, se colocam contra o proletariado, concentrado nas Oficinas Nacionais. Calculam, pois, quais seriam os gastos do Estado com essas oficinas de trabalho proletário, não se conformando com a sua própria situação financeira. Portanto, na Insurreição de Junho, na qual os proletários buscam uma república que defenda os seus interesses de classe, a pequena-burguesia se coloca ao lado da burguesia. Como conseqüência, ao esmagar os operários, essa classe acaba por se colocar nas mãos de seus credores. Porém, a pequena-burguesia é eleita pela burguesia para pagar os déficits do Estado francês. Mais uma vez, num ato de desespero, após a eleição de Napoleão em dezembro de 1848, a pequena-burguesia volta a fazer uma aliança com o proletariado e contra a burguesia. Nesse rápido resumo dos fatos, podemos perceber um dos objetivos da análise de Marx: demonstrar a condição de classe intermediária da pequena-burguesia. A obra indica que ela é uma classe de transição, que se alia tanto à burguesia quanto ao proletariado, dependendo dos seus interesses de classe momentâneos, estes sempre relacionados à defesa de suas propriedades.

Em outros momentos históricos cruciais na história do movimento operário, o papel desempenhado pela pequena-burguesia influencia enormemente o desenrolar da luta de classes. Rosa Luxemburgo se depara, em 1918, com a aristocracia operária do Partido social-democrata alemão (SPD), também uma componente fundamental da pequena-burguesia. A manutenção da democracia burguesa em defesa de transformações graduais que melhorassem as condições de vida da classe operária em oposição ao desenvolvimento de uma revolução social, coloca-se como uma tendência da pequena-burguesia em momentos chave desse processo. "A alternativa: reforma social ou revolução, objetivo final ou movimento é, sob outra capa, a alternativa entre o caráter pequeno-burguês ou proletário do movimento operário" (Luxemburg, 1986, p. 24). A derrota do movimento operário revolucionário em 1918, tragicamente explicitada no assassinato de Rosa Luxemburg e Karl Liebknecht, é parte fundamental do desenrolar dos acontecimentos na Alemanha.

Esses acontecimentos serão analisados por Leon Trotsky (1968). Segundo esse autor apenas após as tentativas revolucionárias de 1918 e 1923 pode-se compreender uma diferenciação mais clara entre pequena-burguesia e proletariado:

Atualmente, esse processo de diferenciação entre a pequena-burguesia e a classe operária chegou a seu termo completo - e é a pequena-burguesia que, temendo

cadernos cemarx, $\mathrm{n}^{\circ} 5-2009 \quad 157$ 
ser absorvida no proletariado, procura defender desesperadamente o seu lugar ao sol, ameaçada de soçobrar definitivamente na proletarização (TROTSKY, 1968, p. 11).

Trotsky (1968) esclarece que, ao buscar evitar sua proletarização a qualquer custo, seu caráter democrático teria se transformado em uma tendência fascista:

Enquanto, em 1848, a pequena-burguesia fazia o proletariado lutar por ela contra a sociedade feudal, em 1933 vê-se mobilizada pelo capital financeiro, como um aríete contra a classe operária organizada: espera assim vencer a crise que corrói o regime e que a leva à miséria, sair da situação desesperada em que se encontra, procurando destruir os fatores de intensificação da implacável luta que enche toda a nossa época, travada entre burguesia e proletariado. Eis o fundamento do fascismo (TROTSKY, 1986, p. 13).

A defesa da democracia pelo SPD teria aberto as portas para o fascismo. Porém, Trotsky afirma ainda que o fascismo não é a única forma contra-revolucionária possível, indicando que o reformismo pode ser uma solução mais viável à burguesia em países onde a classe operária não está suficientemente organizada.

Na ausência de um poderoso partido revolucionário do proletariado, uma combinação de semi-reformas, de frases esquerdistas, gestos ainda mais de esquerda e repressões, pode ser muito mais útil à burguesia do que o fascismo (TROTSKY, 1986, p. 20).

Essas análises de Marx, Luxemburg e Trotsky demonstram a importância da consolidação da pequena-burguesia na dinâmica da luta de classes. Contudo, é necessário ressaltar que essa classe busca somente manter sua condição intermediária, ao mesmo tempo em que é incapaz de projetar autonomamente seu futuro. Essa condição a leva, portanto, na ausência de um forte e unificado projeto da classe operária como solução para determinados momentos de crise social, a apoiar historicamente, ora o reformismo, ora o fascismo. Quanto ao reformismo pequeno-burguês, ainda acrescenta Marx (1980, p. 226):

O caráter peculiar da social-democracia resume-se no fato de exigir instituições democrático-republicanas como meio não de acabar com dois extremos, capital e trabalho assalariado, mas de enfraquecer seu antagonismo e transformá-lo em harmonia. Por mais diferentes que sejam as medidas propostas para alcançar esse objetivo, por mais que sejam enfeitadas com concepções mais ou menos revolucionárias, o conteúdo permanece o mesmo. Esse conteúdo é a transformação da sociedade por

$158 \quad$ Classe média e reformismo altermundialista 
um processo democrático, porém uma transformação dentro dos limites da pequena-

burguesia.

O caráter intermediário e oscilante dessa classe lhe confere uma importância sui generis, pois pode tanto ser fundamental no processo revolucionário ao apoiar, mesmo que com ressalvas e limitações, o projeto da classe operária, quanto pode levar a frente projetos conservadores como o reformismo ou o fascismo, colaborando assim para a quase total desorganização do movimento operário.

\section{Classe Média e Ação Política}

No decorrer do século XX, muito se produziu no âmbito da teoria dos movimentos sociais. A questão da classe, porém, é muitas vezes negada como categoria de análise válida ou é colocada como fator complementar não-essencial na análise dos movimentos sociais. Não pretendemos neste momento nos debruçar sobre a rica discussão presente na vasta bibliografia que aborda esse tema. Porém, gostaríamos de ressaltar a importância de dois autores contemporâneos que chamam a atenção à centralidade do conceito de classes e, mais especificamente, do conceito de pequena-burguesia para a análise dos movimentos sociais.

Brasílio Sallum (2005) tece críticas às diversas teorias que analisam os chamados "Novos Movimentos Sociais" (NMS) ${ }^{4}$ que não consideram a importância da origem de classe média de seus integrantes. É interessante ressaltar que diversos analistas do movimento altermundialista apontam que o movimento seria, em grande parte, conseqüência das mobilizações dos NMS.

Sallum afirma que o abandono da análise das classes sociais para o estudo da ação social é um erro grave. Tal tendência decorreria, em grande medida, do recuo do movimento operário e do surgimento dos NMS. Assim, a antiga análise dualista das classes sociais que se atinha à luta entre burguesia e classe proletária teria sido desestabilizada. Salienta, portanto, a necessidade de se passar a considerar a existência de classes intermediárias como a "nova pequena-burguesia" ao invés de se abandonar completa ou parcialmente a análise de classes. Klaus Eder (2002) produz também estudos interessantes no sentido de trazer novamente o conceito de classe como elemento fundamental na análise dos movimentos sociais. Porém, esses dois autores

4 Os "Novos Movimentos Sociais" seriam os movimentos que surgiram ou se consolidaram a partir das manifestações de 1968, como os movimentos feminista, ecologista, pacifista, estudantil, entre outros. Para uma análise geral dos novos movimentos sociais e sua relação com o espectro político, ver Evers (1983).

cadernos cemarx, $\mathrm{n}^{\circ} 5-2009 \quad 159$ 
se aproximam de análises culturalistas, colocando a classe como fator de limitação da ação dos movimentos, no sentido de que os atores sociais sempre agiriam dentro de certos limites definidos pela classe à qual pertencem. Mas interpretam a classe não como um determinante fundamental dessas ações. Assim, como proposta de definição da classe média e a forma de analisá-la na ação política, amparamo-nos nas análises desenvolvidas por Oliveira (2003) e Saes (1985).

Arriscamo-nos a afirmar que a classe média atual seria a herdeira moderna da pequena-burguesia analisada por Marx (1980). Apesar de ainda manter como característica fundamental sua condição de classe intermediária entre burguesia e proletariado, esta classe deixa de ser pequeno-proprietária e passa a se configurar como uma classe de trabalhadores assalariados. O questionamento que se segue a esta definição é o de como podemos então diferenciar essa classe da classe operária. Segundo Oliveira (2003), a classe média seria composta por trabalhadores assalariados que não estão em contato direto com o processo de produção e que, portanto, não sofrem extração de sua mais-valia. Essa característica confere uma enorme amplitude a essa classe. Saes (1985) mantém-se nessa mesma linha, definindo a classe média fundamentalmente pela não produção direta de mais-valia. E ainda oferece grande contribuição a essa definição ao afirmar que a classe média se caracteriza pela sua enorme heterogeneidade, o que impede a constatação de uma clara unidade ideológica e política. Essa divisão, que se manifestaria mais claramente nos diversos posicionamentos políticos das frações de classe que a compõem, também teria fundamento nas condições de vida de cada fração. $\mathrm{O}$ autor desenvolve, portanto, a necessidade de analisarmos a classe média como classe intermediária a partir de suas frações. Assim, o que une esses diversos grupos em uma mesma classe é sua posição no processo produtivo, isto é, como classe não diretamente produtora de mais-valia. E o que a divide é a diversidade da condição material e sua consequente atuação política.

Devido à amplitude dessa classe e à necessidade de a diferenciarmos da pequena-burguesia analisada por Marx (composta por pequenos proprietários), optamos pela utilização do conceito de classe média, ressaltando sempre a necessidade de especificarmos qual fração dessa classe está sendo analisada, pois suas condições fundamentais de vida no interior de determinada conjuntura determinam diferentemente sua ação política. Atualmente, não estaríamos mais frente àquela pequena-burguesia que se coloca, como um todo, ora ao lado da burguesia, ora ao lado do proletariado.

$160 \quad$ Classe média e reformismo altermundialista 
Deparamo-nos com diferentes frações dessa mesma classe e estas podem adotar, em um mesmo momento histórico da luta de classes, posicionamentos políticos antagônicos entre si. Constatamos, portanto, que, devido ao caráter extremamente fragmentado dessa classe, não se pode afirmar que representantes da classe média como um todo participariam do movimento altermundialista.

Em Pochmann et al (2006) vemos que a classe média brasileira atual seria composta por trabalhadores assalariados do funcionalismo público, do terceiro setor (ONGs) e do setor terciário (serviços), como gerentes de empresas, burocratas, empregados do comércio, empregados de escritório, profissionais de serviços que deixam de ser independentes para trabalhar em grandes firmas, etc. Dados quantitativos mostram que, no Brasil, nas últimas décadas, ocorreu um enxugamento dos empregos de classe média situados na indústria, como gerentes e empregados de escritório. Esses empregos teriam se reduzido bastante com a terceirização e a desverticalização. Assim, grande parte da classe média passaria a ocupar cargos informais no setor terciário como free-lancer e "empresa sem empregado" (pessoa jurídica). Nesse caso, o trabalhador perderia até mesmo a segurança que tinha com o contrato de trabalho.

Em nossos dias, a classe média sofre com as transformações da economia brasileira e tem dificuldades de reproduzir-se. Seus empregos tradicionais se esvaem, sua posição é questionada a todo o momento e as novidades tecnológicas a obrigam a malabarismos de adaptação impensáveis há poucas décadas atrás (POCHMANN et al, 2006, p. 41).

Porém, o capitalismo neoliberal teria atingido de modo desigual as classes médias. No Brasil, acreditamos que os profissionais dos setores privados em expansão (exportações, publicidade, recursos humanos, comunicações e outros) podem ter sido favorecidos com o neoliberalismo. As altas esferas do setor público teriam sido favorecidas pela manutenção da desigualdade e da concentração de renda, mas prejudicadas por algumas medidas neoliberais, como a reforma da previdência. Já o estrato inferior da classe média, tanto do setor público, quanto do privado, teria sido fundamentalmente prejudicado com as reformas econômicas neoliberais implantadas a partir da década de $1980^{5}$, como redução de empregos de alto nível salarial, enxugamento do Estado, privatizações, terceirizações. Essas frações da classe média

5 Importantes análises foram realizadas sobre o desenvolvimento do neoliberalismo nas últimas décadas. Destacamos as análises de Duménil (2004 e 2006) para compreensão do capitalismo em âmbito internacional. Em Boito Jr. (1999) podemos encontrar análises sobre o avanço do neoliberalismo no Brasil e a luta de classes.

cadernos cemarx, $\mathrm{n}^{\mathrm{o}} 5-2009 \quad 161$ 
mais precarizadas, que sofrem com a implantação do modelo capitalista neoliberal, seriam aquelas presentes no movimento altermundialista.

Em nossa pesquisa, analisamos parte da bibliografia sobre o movimento, buscando definir seus traços fundamentais. Seguindo a tendência da desconsideração das classes como fator de análise fundamental dos movimentos sociais, a enorme maioria dos autores analisados não considera esse fator ou o cita apenas de maneira marginal ${ }^{6}$. Apesar dessa constatação, deparamo-nos com alguns dados sobre o Fórum Social Mundial que indicam a composição de classe média do movimento. O Fórum e os movimentos que o compõem são atualmente a mais forte e relevante manifestação do movimento altermundialista.

Sendo a classe média uma classe intermediária - que, portanto, oscila politicamente - extremamente fragmentada e que se define no processo produtivo apenas por não ser diretamente produtora de mais-valia, como poderíamos identificar integrantes dessa classe em uma manifestação política como o Fórum Social Mundial?

Para além de tais definições, Décio Saes (1985) afirma que existem ainda algumas características fundamentais ligadas à posição dessa classe no processo de produção que seriam úteis para identificá-la. Seriam elas: ocupação, alta escolaridade, uma renda superior à da classe operária e, conseqüentemente, uma maior capacidade de consumo. O fator ocupação é o fundamental, pois define o local da classe média no setor produtivo. Como desenvolvido por Pochmann et al (2006), este local de classe média recorrentemente aparece como o setor terciário e o funcionalismo público, setores esses só indiretamente ligados ao processo produtivo. As outras características estão necessariamente associadas como necessidade prévia (escolaridade) ou conseqüência (renda e consumo) desse setor ocupacional.

Pesquisas quantitativas realizadas pelo $\operatorname{IBASE}^{7}$ em algumas edições do Fórum oferecem-nos dados extremamente úteis para indicarmos a composição de classe de seus integrantes. Os dados referentes ao Fórum de 2003 indicam que 73,4\% dos participantes do evento têm alta escolaridade com, pelo menos, ensino superior incompleto. Quanto à ocupação, 43,4 \% são funcionários de instituição privada/ONG e $36 \%$ são funcionários públicos, sendo que $79,5 \%$ trabalham no setor de serviços.

6 Referências esparsas e indiretas sobre a composição social e posição de classe do movimento podem ser encontradas em Klein (2003) e Seoane \& Tadei (2001).

7 As pesquisas realizadas pelo IBASE sobre os Fóruns de 2003, 2005 e 2006 podem ser encontradas em: http://www.ibase.br/modules.php?name=Conteudo\&pid=1070

\begin{tabular}{l|l} 
& Classe média e reformismo altermundialista
\end{tabular} 
Dados do Fórum de 2005 são analisados por Santos (2005), que constata a composição pequeno-burguesa do evento: $43,2 \%$ dos integrantes trabalham em instituições ou ONGs e 36\% são funcionários públicos. Neste sentido, apesar da presença de movimentos sociais, sindicatos e partidos compostos também por operários ou outros trabalhadores das classes populares, a presença da fração pauperizada da classe média seria substancialmente superior. No FSM policêntrico de 2006, uma vez mais podemos notar a presença maciça da classe média a partir das ocupações e alta escolaridade.

Buscamos explanar a importância da pequena-burguesia na luta de classes, bem como a importância da classe média na análise dos movimentos sociais hoje. Indicamos a definição de classe média da qual partimos, com o objetivo de identificar a presença majoritária dessa classe no movimento altermundialista. Buscaremos desenvolver a seguir uma análise de três momentos do movimento (surgimento, reivindicações e alternativas), de modo a explicitar as relações fundamentais entre sua posição de classe média e sua ação política reformista.

\section{A composição de classe média e o reformismo altermundialista}

Partimos do pressuposto de que o caráter reformista do movimento altermundialista fundamentar-se-ia no fato deste estar sob a hegemonia da classe média e, particularmente, das frações da classe média mais prejudicadas pelo modelo capitalista neoliberal. Neste sentido, apresentaremos a seguir - e de maneira resumida - nossa análise de parte da bibliografia sobre o tema, a partir da qual buscamos demonstrar a importância da análise de classes ${ }^{8}$.

Quase todos os autores analisados indicam as manifestações em Seattle (EUA), em 30 de novembro 1999, que ocorreram simultaneamente e em oposição à reunião da Organização Mundial do Comércio (OMC), como o marco de surgimento do movimento. Durante os anos seguintes, houve muitas manifestações globais contra as reuniões das chamadas "organizações multilaterais" (OMC, FMI, Banco Mundial, G8). Após sofrer forte repressão policial, as instituições e indivíduos organizadores dos protestos optaram por uma outra forma de manifestação, com o objetivo de buscar alternativas ao modelo neoliberal, procurando superar o momento meramente negativo, apenas de protesto, em que o movimento se encontrava. Em decorrência disso, em 2001, ocorre em Porto Alegre o primeiro Fórum Social Mundial.

8 Foram analisadas, principalmente: Amin \& Houtart (2003), Klein (2003), Loureiro et al (2002), Santos (2005), Seoane \& Taddei (2001)

cadernos cemarx, $\mathrm{n}^{\mathrm{o}} 5-2009 \quad 163$ 
O que pretendemos apontar de relevante nesse processo é o fato desse movimento ser conseqüência do avanço do capitalismo neoliberal, seu inimigo central, eleito e declarado9. O movimento surge em um momento histórico em que a classe média já há alguns anos sofria com a precarização de suas condições de vida, perdendo cada vez mais o acesso a bens como educação, saúde e previdência social. Isso se explicita no Brasil pelos altos índices de desemprego que atingiu essa classe ${ }^{10}$. Apesar desse processo ocorrer mais lentamente nos países centrais, as condições da classe média européia também se deterioram. Um exemplo interessante são as manifestações contra o Contrato do Primeiro Emprego (CPE) na França em 2006, promovidas fundamentalmente por jovens universitários de classe média, bem como as atuais manifestações - abril e maio de 2008 - de professores e alunos do ensino médio contra a supressão de cerca de 11.000 postos de trabalho, sancionadas pelo atual governo francês. Neste sentido, o avanço neoliberal nos países centrais se manifesta através do desmonte do Estado de bem-estar social. Devemos considerar inclusive que esse aparato provia uma grande quantidade de empregos à classe média, bem como benefícios essenciais para sua sobrevivência, como saúde e educação públicas. Já nos países periféricos é possível observar, na esfera econômica, o processo de reestruturação produtiva, através do qual a burguesia industrial recorre a medidas como a terceirização, buscando-se reduzir seus custos com mão-de-obra, através da eliminação de cargos de gerência e de administração dentro das fábricas, cargos tipicamente de classe média. Poderíamos, neste sentido, relacionar o surgimento do altermundialismo como resposta às conseqüências que a globalização neoliberal causa para os grupos sociais que o compõem majoritariamente. Assim se explica o fato desse movimento lutar contra a roupagem neoliberal do capitalismo e não contra o sistema capitalista, questão diversas vezes colocada em várias obras analisadas.

Os traços fundamentais desse movimento são evidenciados por algumas de suas reivindicações centrais: a implantação da Taxa Tobin ${ }^{11}$ e de um sistema regulador

9 Apesar do movimento analisado ser extremamente fragmentado e plural, sendo composto também por movimentos de contestação do capitalismo, pensamos haver uma tendência hegemônica no altermundialismo. A partir da análise da bibliografia disponível, consideramos que essa tendência é o reformismo. Importante ressaltar, contudo, que existem movimentos e organizações, apesar de minoritários, verdadeiramente combativos, que procuram romper o reformismo presente no evento.

10 Esses e outros dados podem ser encontrados em Pochmann et al (2006).

11 A Taxa Tobin é uma proposta de taxação da circulação do capital financeiro em escala global, sendo que a renda seria revertida a um fundo mundial contra a pobreza, a destruição do meio ambiente e de defesa dos direitos humanos. Esta medida é defendida principalmente pela ATTAC, Ong de origem francesa.

164 Classe média e reformismo altermundialista 
do sistema financeiro internacional, a anulação da dívida externa dos países do terceiro mundo, o estabelecimento de novas formas de regulação do comércio internacional, a penalização de empresas que desrespeitam o meio ambiente e os direitos trabalhistas, a reforma agrária nos países que ainda não a empreenderam, a instituição obrigatória de regras internacionais de respeito ao meio ambiente como o Protocolo de Kyoto, a proibição da produção e da comercialização de produtos geneticamente modificados, a democratização dos meios de comunicação, entre outros.

No entanto, mesmo que essas reivindicações possuam um caráter progressista, elas se colocam sempre na perspectiva de reforma do sistema capitalista, como formas de contenção do sistema neoliberal que tanto assola a classe média. Assim, seriam empreendidas transformações dentro do sistema sem eliminá-lo. Essa seria uma tendência típica de um movimento de classe média, pois, como vimos, esta classe não almeja reverter completamente a estrutura social, desejando claramente manter uma posição privilegiada. Neste sentido, Naomi Klein (2003), uma das ideólogas mais proeminentes do movimento, expressa a visão, encontrada constantemente na bibliografia analisada, de que o grande problema mundial seria a exclusão social, e não mais a exploração. O movimento deveria, portanto, lutar para que os excluídos dos benefícios do sistema passassem a desfrutar esses benefícios. Esse deslocamento da visão do problema resulta em uma luta que se dirige contra o neoliberalismo - que haveria intensificado este processo de exclusão - e não contra o capitalismo que, afinal, em nossa visão continua tendo como sua base fundamental o processo de exploração do trabalho. Nesse sentido, podemos compreender que a classe média, combatendo o neoliberalismo, deseja voltar a desfrutar dos benefícios que tinha anteriormente. Esse movimento possui também preocupações com as classes populares, contudo, essas questões parecem estar sempre subordinadas às necessidades da classe média. Se grandes transformações são necessárias para a melhora das condições de vida das classes populares, elas não estão atualmente em pauta. Marx (1980) explicita na passagem a seguir que a pequena-burguesia pode apresentar intenções altruístas, mas sempre se limitam à sua condição de classe intermediária que luta pela manutenção de sua condição e não pela revolução social:

Só que não se deve formar a concepção estreita de que a pequena-burguesia, por princípio, visa a impor um interesse de classe egoísta. Ela acredita, pelo contrário, que as condições especiais para sua emancipação são as condições gerais sem as quais a sociedade moderna não pode ser salva nem evitada a luta de classes (MARX, 1980, p.

cadernos cemarx, $\mathrm{n}^{\mathrm{O}} 5-2009 \quad 165$ 
227).

É importante apresentarmos algumas alternativas propostas por esse movimento que vêm a reforçar a hipótese que guia este artigo. O Fórum Social Mundial foi criado principalmente por movimentos sociais, ONGs e outras instituições, com o objetivo de unir os diversos movimentos que compõem o altermundialismo para a formulação de alternativas para a construção de um "outro mundo possível". Porém, o Fórum já se encontra em sua sexta edição e não parece ter apresentado alternativas concretas de luta. Este evento, na medida em que não resulta em acumulação organizativa seria, na nossa concepção, inócuo. Ao se negar a construir um programa político comum a todos os movimentos nele presentes, esse evento se limita a uma espécie de apelo lançado ao ar na esperança de que alguma entidade poderosa se sensibilize e assuma a luta.

Assim como as manifestações, o Fórum parece ter um valor simbólico por promover a tão aclamada "luta ideológica" contra o neoliberalismo. Após sete anos de sua primeira realização, as várias edições do evento não parecem avançar no sentido da consolidação de propostas concretas. A principal alternativa que se coloca seria a conquista de um processo de inclusão através de práticas democráticas. Assim, com a ampliação destes "espaços de democracia participativa" como o Orçamento Participativo, por exemplo, conquistar-se-ia a possibilidade de influência nas políticas locais, o que impediria o avanço neoliberal. Nesse sentido, o movimento parece se negar a refletir sobre o poder repressor do Estado e as estruturas que garantem que as classes dominantes mantenham sua posição no poder, impedindo que outras classes ou movimentos tenham qualquer tipo de poder de decisão. Além disso, a famosa afirmação da necessidade do "agir local para mudar global" não se realiza pelo fato de os movimentos não estarem verdadeiramente enraizados nas comunidades locais, crítica apresentada e desenvolvida por Santos (2005). O movimento propõe, portanto, alternativas limitadas que se colocam de acordo com o alcance de transformação que essa classe almeja. Esta seria gradual, local e de combate ao neoliberalismo. A estrutura social capitalista seria mantida, mas uma nova forma de bem-estar social, promovida pela sociedade civil, seria criada, buscando incorporar a questão social ao sistema capitalista e construindo, assim, um "capitalismo humanizado". Contudo, mesmo a luta pela ampliação dos direitos universais dentro dos limites da sociedade burguesa continua a se colocar de forma fragmentada, e o Fórum não parece ser capaz de criar frentes de luta eficientes e com uma unidade ideológica definida, o que poderia

166 Classe média e reformismo altermundialista 
possibilitar em nossa visão uma luta mais ampla contra o capitalismo.

De acordo com o que apresentamos no início deste artigo, é importante que não percamos de vista que, nos diversos momentos históricos em que o movimento operário é cooptado pela ideologia pequeno burguesa, tem-se um grande retrocesso na organização política do proletariado, o fortalecimento da classe burguesa e nascimento de um novo momento de forte subordinação do trabalho ao capital.

\section{Conclusão}

Gostaríamos de concluir estas linhas apontando para a necessidade de se buscar compreender as origens e a história da classe média, sendo esse elemento fundamental para a análise da luta de classes atual. É importante considerar que esta classe tem grande peso na organização política e na luta da classe operária. Muitos autores colocam o potencial progressista desses movimentos que propõe a reforma, sem refletir atentamente para as conseqüências e influências dessas manifestações na luta social. Colocamos, portanto, um questionamento final com relação à atuação política de classe média: Estando essa classe em uma posição intermediária e buscando em última instância a manutenção e a melhoria de suas condições de vida, é possível que ela rompa com seus limites de classe e se coloque como classe-apoio do movimento operário sem subverter os objetivos de revolução social que garantiriam uma melhora significativa das condições da classe trabalhadora como um todo? Quais os limites desse progressismo de classe média? Quais suas conseqüências para a luta de classes atual?

Podemos não chegar a respostas definitivas e seguras a essas questões nos limites de nossa pesquisa. Porém, consideramos sua problematização essencial para a teoria marxista, a fim de compreender as potencialidades e limites das manifestações sociais que observamos e vivenciamos nas últimas décadas.

\section{Bibliografia}

AMIN, Samir; HOUTART, François (Orgs.). Mundialização das Resistências: o estado das lutas. São Paulo: Cortez, 2003.

BOITO, Armando. Política neoliberal e sindicalismo no Brasil. São Paulo: Xamã, 1999.

DUMÉNIL, Gérard; LÉVY, Dominique. "Une théorie marxiste du néolibéralisme". In : Actuel Marx, Fin du néoliberalisme? Paris; PUF, 2006, nº 40, p.24-29.

cadernos cemarx, $\mathrm{n}^{\mathrm{O}} 5-2009 \quad 167$ 
"O imperialismo na era neoliberal". In: Crítica Marxista. Rio de Janeiro: Revan, 2004, nº 18, p. 11-36.

EDER, Klaus. A nova política de classes. Bauru; São Paulo: Edusc, 2002.

IBASE. Fórum social Mundial - raio X da participação no Fórum policêntrico, 2006.

KLEIN, Naomi. Cercas e Janelas: na linha de frente do debate sobre globalização. Rio de Janeiro: Record, 2003.

LOUREIRO, Isabel; LEITE, José Corrêa, CEVASCO, Maria Elisa. (Orgs.). O Espírito de Porto Alegre. São Paulo: Paz e Terra, 2002.

LUXEMBURG, Rosa. Reforma ou Revolução? São Paulo: Global, 1986.

MARX, Karl; ENGELS, Friedrich. Manifesto do partido comunista. Petrópolis: Vozes, 1988.

“O Dezoito Brumário de Luís Bonaparte”. In: Obras Escolhidas, vol. 1, São Paulo: Alfa-Ômega, 1980.

OLIVEIRA, Francisco de. Crítica à Razão Dualista. São Paulo: Boitempo, 2003.

POCHMANN, Marcio et al. Classe Média - Desenvolvimento e Crise. São Paulo: Cortez, 2006.

SAES, Décio. Classe média e sistema político no Brasil. São Paulo: T. A. Queiroz, 1985.

SALLUM JR., Brasílio. “Classes, cultura e ação coletiva”. In: Revista Lua Nova. São Paulo: USP, $n^{\circ}$ 65, 2005.

SANTOS, Boaventura de Souza. O Fórum Social Mundial: manual de uso. São Paulo: Cortez, 2005.

SEOANE, J e TADDEI, E. (Orgs.) Resistências Mundiais: de Seattle a Porto Alegre. Petrópolis: Vozes, 2001.

TROTSKY, Leon. Revolução e contra-revolução na Alemanha. Rio de Janeiro: Laemmert, 1986.

168 Classe média e reformismo altermundialista 